\title{
An Empirical Study of Performance Appraisal and Career Opportunities
}

\author{
Arngrim Hunnes (Corresponding author) \\ Department of Economics and Business Administration, University of Agder \\ Box 422, NO-4604 Kristiansand, Norway \\ Tel: 47-3814-1514Ｅ-mail: arngrim.hunnes@uia.no
}

Ola Kvaløy

University of Stavanger Business School

NO-4036 Stavanger, Norway

Tel: 47-5183-1582Ｅ-mail: ola.kvaloy@uis.no

\author{
Klaus Mohn \\ University of Stavanger Business School \\ NO-4036 Stavanger, Norway
}

Tel: 47-5183-2258 E-mail: klaus.mohn@uis.no

Received: August 12, 2011

Accepted: September 15, 2011

Published: January 1, 2012

doi:10.5539/ijbm.v7n1p22

URL: http://dx.doi.org/10.5539/ijbm.v7n1p22

The research is financed by the Research Council of Norway.

\begin{abstract}
Using survey data from a large international oil company, this econometric study explores the perceptions of performance appraisal and career opportunities on one hand, and how this is dependent on variation in properties and characteristics of the local working environment on the other hand. Perceptions indicate that performance and payoff are better balanced among women than among men. Moreover, the connection between perceived achievement and appreciation is strengthened by time of service for leaders, but not for employees in non-managerial positions. Finally, perceptions of performance appraisal and career opportunities depend on characteristics of the local work environment, with positive influence from key phenomena like change capability, competency focus, trust and identity.
\end{abstract}

Keywords: Performance appraisal, Career opportunities, Survey data, Probit models

\section{Introduction}

The key idea of performance appraisal is to establish a reward system that optimizes the efforts and contribution of leaders and employees to the general performance of their organisation. As noted by Cleveland, Murphy, and Williams (1989), the propagation of performance appraisal systems is motivated by a broad range of concerns, including promotions, terminations, salary administration, and the development of adequate competence and expertise. Performance appraisal may be useful both in the cross-sectional dimension (for comparison between individuals) and for the time dimension (for comparison of individual performance over time).

There is a large body of research on performance appraisal systems. The early literature was dominated by psychologists and focused on the psychometric properties of appraisal, in particular the role of supervisors and the precision on their performance evaluation (see Milkovich and Wigdor, 1991, for a survey). Recent psychological literature has put more emphasis on worker reaction to appraisals and the social context in which 
appraisal occurs (see Keeping and Levy, 2000; Levy and Williams, 2004). Issues of employee satisfaction with performance appraisal systems are explored by Boswell and Benson (2000) and Brown and Benson (2003), who both argue that individual involvement and development opportunities play an important role for the success ratio of performance appraisal systems. Kuvaas (2006) investigates the relationships between performance appraisal on the one hand, and employee outcomes in terms of performance, organisational commitment and turnover intention on the other. He finds that motivational issues play an important role for the efficiency of performance appraisal systems. The role of trust for the acceptance of performance appraisal has also caught extensive attention in recent research (e.g., Zaheer, McEvily and Perrone, 1998; Reinke, 2003; Kickul, Gundry, and Posig, 2005). Results from these studies clearly suggest that the level of trust between employee and leader is an important predictor for the general acceptance and advancement of performance appraisal systems.

Economists started to gain a theoretical interest in performance appraisal in the 1970s when economics of incentives and asymmetric information made its way into the theoretical literature. However, it is not until recently that economists have begun to investigate performance appraisal empirically. Key findings from this literature indicate a wider dispersion of labour income due to performance appraisal, both within each firm (Barth, Bratsberg, Hægeland and Raaum,2008) and for society as a whole (Lemieux, MacLeod, and Parent, 2009). Grund and Sliwka (2009) argue that the prevalence of performance appraisal correlates negatively with risk aversion, which again is an increasing function of age, and which is more pronounced among women. Consequently, performance appraisal systems are most common among young and middle-aged men. Yet, there is still surprisingly little empirical research on the link between performance appraisal and these kinds of background variables.

The main objective of this study is to contribute to the relatively sparse empirical literature on perceptions of performance appraisals by using a large and unique set of survey data from a large international oil company. Hence, this is a study of one firm only, rather than a broad economy-wide cross-sectional assessment (e.g., Grund and Sliwka, 2009). One advantage with firm studies is that to some extent they control for sorting effects, since the employees of the data set to a large extent are exposed to common organizational changes and business cycles (e.g. Lazear, 1998; Marsden, 2004).

In the study we combine knowledge of the formal appraisal system that the employees are exposed to, with their subjective perception of performance appraisal. The employees are asked to what extent performance forms the basis for recognition and reward, and the answers to this question are our dependent variables in the econometric analysis. This is important since formal appraisal systems such as bonus contracts, commissions and piece rates are just a small part of total performance appraisal. Performance-related reward, for instance, is often based on supervisors' subjective evaluation (see MacLeod, 2003 for analysis), and these evaluations are not captured in empirical studies of formal incentive systems. Our measure of performance appraisal includes elements of reward and recognition and might be seen as a backward-looking indicator. On the other hand, individual perceptions and judgments regarding career opportunities may be seen as a forward-looking measure of performance appraisal (e.g., Prendergast, 1999). Accordingly, we estimate and present econometric models for both these perspectives.

Our main results are as follows: First, the perceived alignment of efforts and rewards is more pronounced among women than for men. Second, we find that the connection between perceived achievement and appreciation is strengthened by time of service for leaders, but not for employees in non-managerial positions. Third, we find that perceived performance appraisal and career opportunities are linked to characteristics of the local work environment. Finally, our results demonstrate that the mechanics of backward-looking performance appraisal (reward and recognition) is not necessarily identical to the formation of expectations with respect to future performance appraisal (career opportunities).

The paper is organised as follows. Section 2 gives a brief overview of the processes of performance appraisal in the company which forms the subject of our study. The sample is presented and variables are defined and discussed in Section 3. An econometric model is outlined and estimated in Section 4, with subsequent discussion of the key results. Summary and concluding remarks are offered in Section 5.

\section{Performance appraisal in Statoil - a brief overview}

Statoil is an international oil and gas company with 25,000 employees and business activities in 34 countries. As the former national oil company of Norway, Statoil was established in 1972 to take part in the development of oil and gas resources on the Norwegian Continental Shelf. Over the years, gradual commercialisation, deregulation and internationalisation culminated with the partial privatisation and listing of the company in June 
2001. Statoil merged with Hydro's oil and gas activities in October 2007 and currently ranks among the 10 largest international oil and gas companies in the OECD area.

The company advertises a reward concept that includes both intangible benefits such as professional development and more tangible rewards such as employment benefits dependent upon position, role, and in some cases geographic location. Appraisals of individual performance are claimed to be based not only on specific delivery, but also on social behaviour. As part of the corporate management system, a designated process ("People@Statoil") is run on an annual cycle to manage people, performance, development and deployment. Goals relating to individual performance and behaviour are linked to strategic objectives, which also set the direction for personal development and career plans.

Reward packages are designed to be competitive in relevant market segments and regions where the company operates, and include bonus and share savings schemes in addition to base salary and other compensations. In their recruitment documents, the company also emphasizes welfare, wellbeing, continuous competence upgrades, and a large internal job market. Pension plans and insurance arrangements, sick leave, flexible work arrangements and paid holiday may also be seen as parts of the reward system.

For leaders as well as employees, individual fixed salaries are claimed to reflect responsibilities, experience and competence. Fixed salaries are evaluated in a yearly process of performance appraisal, with follow-up meetings between superiors and subordinates throughout the year. In this process, equal weight is put on individual deliveries and personal behaviour. All employees are included in a corporate group bonus programme, with a bonus opportunity limited to 5 per cent of the annual fixed salary (2006). The corporate bonus is calculated annually based on financial performance relative to other large international oil and gas companies.

A selection of executives in key specialist and administrative positions are included in an annual variable pay scheme as well as a long-term incentive scheme, whereby bonus entitlements are accumulated on a rolling 3-year basis. Leaders are subject to a yearly 360 degree evaluation process, with inputs and assessments also from colleagues in other parts of the company (e.g., supplying units and client units).

\section{Data and variables}

\subsection{Sample}

Our data source is the annual survey of the work environment and organisational issues in Statoil. This so-called Global People Survey was undertaken during the period 15 September to 27 October 2006, and was sent out to 16,000 leaders and employees in 14 European countries. (Note 1) With a response rate of 83 per cent, more than 13,000 forms were retrieved from the survey. Our sample is the 2006 survey, with just above 12,000 responses for the variables we will study. Statoil's Global People Survey 2006 requested the evaluation of 60 questions and statements on a measurement scale ranging from 1 to 6 . Subjects covered a wide range of topical areas, including (but not limited to) performance culture, change capability, competence and expertise, trust and identity, and HSE issues. Moreover, the response forms offer data for background information on gender, age, seniority, leader/non-leader position, country of work and organisational belonging, offering information for a wide range of empirical assessments.

\subsection{Dependent variables}

As explained in the introduction, we want to investigate factors behind perceptions regarding both performance appraisal (backward-looking indicator) and career opportunities (forward-looking indicator). As the performance appraisal variable $(P A)$, we select the response given to the statement:

\section{"In my entity, performance forms the basis for recognition and reward."}

Observe first that the statement invites a genuinely subjective evaluation, without any rigid link to observables or measurable phenomena. Neither is it suitable for inference on recognition and reward. Rather, the statement addresses the relation between performance on the one hand, and recognition and reward on the other. The information which is gained from this approach provides insight on the perceived connection between efforts and reward. Hence, we want to explore factors that may influence the perceived alignment of performance and payoff as implied by Statoil's system of reward and recognition.

As noted by Prendergast (1999), career opportunities may be seen as an option to renegotiate the employment contract based on previous performance. This forward-looking perspective on performance appraisal may also be addressed in our data set. Consequently, the point of departure for our second dependent variable is a statement concerning individual career opportunities $(\mathrm{CO})$ :

\section{"I am satisfied with my career opportunities in Statoil."}


Observe again that the question is subject to a strictly subjective evaluation and that no specific measures are included or implied, neither for career opportunities nor for the degree of content. As such, the statement simply evaluates the sentiment in each respondent to produce a simple indicator of general complacency with respect to career opportunities.

Average scores for the dependent variables are depicted in Figure 1. Ratings among leaders are somewhat higher than among employees for both variables. The same is true for women. For the system of performance appraisal, the gap between leaders and employees is significant. Appraisal systems in terms of individual performance pay and bonuses are more advanced for leaders than for employees, whose economic reward is largely restricted to their annual wage negotiations (in addition to social recognition and career opportunities). As we see from the right-hand panel of Figure 1, a similar pattern is reproduced for the individual perception of career opportunities. However, the difference between leaders and employees is less pronounced for this variable, as is the difference between women and men. For more details on average scores, see Appendix 1.

\subsection{Design of independent variables}

Our scope of research involves regressions for the two indicators of performance appraisal and career opportunities against relevant background variables. Moreover, we will seek to establish robust relations between our two dependent variables on the one hand, and other elements of Statoil's Global People Survey on the other. Our data set allows a split between men and women, and we will therefore test whether perceptions of performance appraisal and career opportunities vary systematically across gender. Further, respondents are asked for information on seniority. More specifically, they tick one of three boxes to indicate the length of service with the firm (less than 3 years, 3-10 years or more than 10 years). In our statistical analyses, we apply dummy variables to test for the role of seniority for the perception of performance appraisal and career opportunities.

Our data offer lots of additional information that could shed additional light on perceptions of performance appraisal and career opportunities. Due to mechanisms of self-selection (e.g. Lazear, 1998; Marsden, 2004), we should expect employees in a performance-oriented working environment to be more pleased with the system of performance appraisal than employees in units where performance and merit are of lesser importance. For example, employees within corporate finance and commodity trading units should be more inclined to give a high score for performance appraisal than employees in blue-collar operational units with a high degree of collective bargaining (see also Grund and Sliwka, 2009). (Note 2) Moreover, employees and organisational units marked by general distrust and an unsound working environment would think differently about performance appraisal and career opportunities than people with trustworthy leaders in a healthy part of the organisation (e.g., Zaheer et al., 1998; Reinke, 2003; Kickul et al., 2005).

To grasp this variation in properties and characteristics of the local working environment, we design four index variables, based on factor analysis of relevant groups of items (see Pett, Lackey, and Sullivan, 2003). An overview of retained items, index variables and key statistics is presented in Table 1 . We report eigenvalues for two potential principal components, $E V_{l}$ and $E V_{2}$. A substantial drop is observed between $E V_{l}$ and $E V_{2}$ for all index variables. With a maximum for the second eigenvalue of 0.37 (TRID), this suggests that our preferred index-variables represent a reliable clustering of items. The clustering of items is backed up by high factor loadings $\left(\lambda_{1}\right)$, indicating a specific underlying dimension for all our index variables. Moreover, the reliability of our index-variables is also supported by high internal consistency, as measured by Cronbach's $\alpha$ (Cronbach, 1951). Finally, values above 0.45 for all communality measures $(C)$ indicate a low degree of specific variance, implying that each of our index variables is quite well explained by one single factor.

\subsubsection{Change capacity}

The first index variable $(C H N G)$ relates to change capacity in the local work place, including items concerning creativity, internal and external follow-up and feedback, and implementation of improvement efforts. The underlying hypothesis is that an agile working environment, with capacity and capabilities for change, should also affect the balance between expectations and fulfilment in terms of performance appraisal (e.g., Offstein, Gnyawali and Cobb, 2005).

\subsubsection{Competence and expertise}

The second index variable (EXPT) evolves around competence and expertise and represents a synthesis of items related to human capacity utilization, development and exchange of competence. These qualities of the local work place may be seen as a reflection of active HR management (e.g., Lado and Wilson, 1994; Svetlik and Stavrou-Costea, 2007), which is potentially important both for the job motivation of the individual employee and for the performance of the organisation. Responders who would emphasize the connection between competence 
and performance should tend to cluster in organisational units where this relation is appreciated. The role of our EXPT variable is therefore to test if these leaders and employees also feel that their inclination for competence and expertise is appropriately rewarded.

\subsubsection{Trust and identity}

Issues of trust have become increasingly important in the literature on organizational culture and performance in general (e.g., Kickul et al., 2005), and specifically for the acceptance of performance appraisal systems (e.g., Reinke, 2003; Kuvaas, 2006). The third index variable represents a proxy for trust and identity (TRID), based on questions and items concerned with confidence in management, as well as issues of strategy, collaboration and reputation. As this variable captures trust both in the immediate leader as well as corporate management, it covers both the relationship-based and the character-based perspective of trust (e.g., Dirks and Ferrin, 2002).

\subsubsection{Health, environment and safety}

The last index variable (HSEC) accounts for the prevalence and importance of concerns for health, environment and safety issues in the local organisation of the surveyed persons. As evident from the definition presented in Table 1, this variable is largely based on internal welfare and safety issues rather than corporate environmental concerns. In contrast with the other index variables, the $H S E C$ variable is expected to exert a negative influence on the performance appraisal variable, but not necessarily for the perception of career opportunities.

Finally, there is good reason to believe that all the above mechanisms will vary significantly between leaders and non-leaders. For example, long experience with the firm may be positive for the acceptance of performance appraisal systems among leaders, as leaders belong to a group which is systematically rewarded for performance. On the other hand, the group of people with long experience with the firm as employees will include persons who have never succeeded in becoming leaders. For this group, seniority might disturb the perceived balance between achievements and appreciation. Accordingly, we estimate our model in three versions: one for the full sample of respondents, one for the sub-sample of leaders, and one for the sub-sample of employees. Descriptive statistics for these three samples are presented in Table 2.

\section{Econometric model and estimation results}

Our econometric is specified to account for the special properties of our data, which is based on a set of ordinal information from Statoil's Global People Survey. Specifically, our dependent variables may take any value on an ordinal scale from 1 to 6 , whereas the dummy variables for gender and seniority take either 0 or 1 as their value. We know that five is a better response than four, and this information should be acknowledged and exploited in our econometric estimation. However, we are not in a position to say that the difference between three and four is half the importance of the difference between one and three. On the other hand, aggregation has transformed the ordinal scale of the constituent variables to a continuous scale for the five index variables. Still, the variation of the index variables is restricted to the interval $[1,6]$. Based on these special properties of our data, we apply a generalisation of the probit model for categorical choice, the so-called ordered probit model (Zavoina and McElvey, 1975; Greene, 2003). At the core of our model is an underlying linear relationship between a latent variable $\left(y^{*}\right)$ and a set of explanatory variables $(x, z)$ :

$$
y^{*}=x \beta+z \gamma+e,
$$

Where $x$ represents the vector of dummy variables for gender and seniority, $z$ is the vector of index variables, and represent the set of coefficients to be estimated, and $e$ is an error term with the standard white-noise properties. What we observe, however, is not $y^{*}$, but its ordered approximation $(y)$, with discrete values in the interval $[1,6]$. With $1,2, \quad 3,4, \quad 5$ as the relevant set of threshold parameters (or cut points), the observed variable is now assumed to satisfy the following definition:

$$
\begin{array}{lll}
y=1 & \text { if } & y^{*} \leq \alpha_{1} \\
y=2 & \text { if } & \alpha_{1}<y^{*} \leq \alpha_{2} \\
& \vdots & \\
y=6 & \text { if } & y^{*}>\alpha_{5}
\end{array}
$$

The probability of observing $y^{*}$ at a specific value for the recorded response may now be stated as: 


$$
\begin{gathered}
p(y=1 \mid x, z)=p\left(x \beta+z \gamma+e \leq \alpha_{1} \mid x, z\right) \\
p(y=2 \mid x, z)=p\left(\alpha_{1} \leq x \beta+z \gamma+e<\alpha_{2} \mid x, z\right) \\
\vdots \\
p(y=6 \mid x, z)=p\left(x \beta+z \gamma+e>\alpha_{5} \mid x, z\right)
\end{gathered}
$$

Maximum-likelihood procedures are applied to estimate the coefficient vectors and of Equation (2), along with the threshold parameters $\alpha_{1}, \ldots, \alpha_{5}$. The estimated coefficients and measure the change in the average score for the dependent variable in response to a one-unit change in dummy variables and explanatory variables, respectively. (Note 3)

Estimation results for perceptions of performance appraisal and career opportunities are presented in Table 3. (Note 4) The full sample consists of approx. 12,500 observations in both cases. The sample split between leaders and non-leaders leaves some 1,950 observations (16 per cent) for the population of leaders, and around 10,500 observations (84 per cent) for the population of employee respondents. The statistical properties of all econometric models are satisfactory. Estimated parameters take signs according to expectations, and most of them pass the tests of statistical significance at the 1 per cent level. (Note 5) Moreover, all tests for joint significance strongly indicate that our explanatory variables are highly valid. Statistical fit, in terms of pseudo $R^{2}$, suggests that our variables capture 18-21 per cent of the variation in the data set. (Note 6)

Our estimated model for the perception of performance appraisal produces a positive coefficient for our female gender dummy, indicating that women feel that efforts and rewards are more aligned than the perception would suggest for men. The estimated gender difference is also exactly twice as large for leaders as for the population of employees. This result is in contrast with previous findings for cross-sectional data of economy-wide survey information (e.g., Grund and Sliwka, 2009), whereby PA systems are found to be more attractive for men than for women. This difference in results may be due to the difference in data types, as economy-wide data is more sensitive to selection bias. An alternative interpretation is based on Sweeney and McFarlin (1997), who argue that women are less concerned with distributive justice than men. (Note 7) Finally, the systematic discrepancy between women and men in their evaluation of the PA system could also reflect different information sets and gender-specific references (Hind and Baruch, 1997; Donohue and Heywood, 2004).

For the full sample, our results suggest that the perceived balance between achievements and acknowledgement is skewed by length of service with the company. Both dummy variables for seniority are negative and statistically significant. The coefficient for Seniority 1 suggests that the perception among people who have stayed with the company for 3-10 years is that efforts and rewards are less balanced than the perception would suggest among people who have been with the company for a shorter period of time. Moreover, the higher value for Seniority 2 than for Seniority 1 suggests that people who have stayed with the company for more than 10 years feel that the link between performance and recognition is even weaker than for people with intermediate length of service. This result is consistent with previous empirical findings which imply that preferences for merit-based pay are negatively related to years of service (e.g., Koys, Keaveny, and Allen, 1989). It is also in line with economics literature arguing that employees are more likely to be evaluated and appraised in the beginning of their career (Brown and Heywood, 2005). A theoretical explanation for this finding is that evaluation and monitoring is more important early in a worker's career for the purposes of determining ability and job assignment (Jovanovic, 1979; Lazear, 1990). Moreover, senior workers are more likely to have developed firm specific human capital, which reduces the need for monitoring since the chance that other firms will pay them more is smaller (Lazear, 1998).

Interestingly, these results are clearly driven by attitudes among employees in non-managerial positions, who represent 84 per cent of the full sample. For leaders, we find that the balance between perceived achievement and appreciation is improving with length of service. In line with findings by Taylor, Masterson, Renard, and Tracy (1998), our estimated model for the sub-sample of leaders suggests that the perceived connection between achievements and appreciation is stronger for managers and employees who benefit most from the prevailing PA system. A likely explanation is that leaders (more often than regular employees) are exposed to formal incentive schemes based on individual performance, and that these schemes are not affected by seniority. Moreover, seniority may increase the indispensability of the leaders' human capital, and as shown by Kvaløy and Olsen (2011), indispensable human capital calls for individual performance pay, since employees can threaten to walk away if they are not paid a "fair share" of their value-added.

Our results suggest that the perceived balance between individual achievement and acknowledgements is higher in parts of the organisation characterised by high willingness and capability to change. We therefore find support 
for the hypothesis that an agile working environment, with focus on competitiveness and change, is normally associated with a more direct link between individual performance and rewards than what is typical for more lenient and sheltered parts of the organisation (e.g., Offstein et al., 2005).

As we would expect, units and departments focusing on active management of skills and expertise (EXPT) are also associated with higher scores for the approval with performance appraisal systems. In this respect, there is only a slight difference between leaders and employees. Individuals who are especially concerned with the kind of qualities represented by the EXPT variable may seek job opportunities on that account. With this interpretation, our results suggest that they feel that their qualities and interests are appreciated by the system of performance appraisal. In a general context our EXPT variable may be associated with the local prevalence of active human resource $(H R)$ management, whereby competence and training may be seen as an integrated part of the compensation scheme (e.g., Lado and Wilson, 1994). At this point our results therefore suggest that individual achievements and rewards are balanced by a competency-based view on $H R$ management, as evident through high scores for the EXPT variable.

However, just as important as attributes relating to competence and expertise are issues of organisational and leadership confidence, according to our results. The index variable for trust and identity (TRID) takes a positive, sizeable and precisely estimated coefficient. Interestingly, this coefficient does not show significant variation between leaders and employees, suggesting that the role of trust and identity issues represents a general mechanism. Our results at this point are in line with previous studies (e.g., Gebris and Ihrke, 2000; Reinke, 2003; Kuvaas, 2006), which also find that the level of trust between employees and their leaders is an important predictor for the acceptance of performance appraisal systems.

Finally, our estimated model for performance appraisal perception approval is supportive of the hypothesis that extensive HSE concerns tend to suppress the acceptance of prevailing systems of performance appraisal. One possible explanation is that merit-oriented leaders and employees see HSE regulations as an impediment to their pursuit of performance, creating a wedge between their performance appraisal and their personal undisturbed potential. A complementary explanation is that HSE concerns are especially far-reaching for industrial, blue-collar workers, for example in offshore oil and gas activities. These parts of the organisation are also characterised by a high degree of collective bargaining, leaving less room for individual performance appraisal. This interpretation is supported by the fact that the negative relationship can not be re-produced for our sub-sample of leaders.

In a wider context, career opportunities may be seen as part of an expanded system of performance appraisal, with a more forward-looking allusion (Prendergast, 1999). We therefore re-estimate the same model as presented for performance appraisal acceptance, but now with perceived career opportunities $(C O P)$ as the dependent variable. Results are presented in the right panel of Table 3 . There is a gender difference also in this model, but not among leaders. Female employees, on the other hand, report a somewhat higher degree of satisfaction with their career opportunities than men. However, whether this is a reflection of differences in ambitions or differences in real opportunities can not be determined by our results. Not surprisingly, personal fulfilment in terms of career opportunities is negatively influenced by length of service with the company. Note that the effect of seniority is smaller among leaders than for employees. Moreover, the significant difference for employees occurs when they pass three years of experience, with only a small additional effect for the old-timers. For leaders, the effect of passing the 3-year threshold is smaller than for employees, and there is also a somewhat larger additional effect for the old-timers in our sub-sample of leaders.

Interestingly, we see that the $C H N G$ variable takes a significantly negative coefficient, both for leaders and for employers in non-managerial positions. This is also an indication that for the parts of the organisation characterised by restructuring and rapid change, potential rewards in terms of career opportunities tend to be dominated by personal non-economic costs relating to job-insecurity, challenges and stress (King, 2000). (Note 8)

As for the $P A$ model, the dimensions of expertise (EXPT) and trust (TRID) also exert a clearly positive influence on perceived career opportunities $(C O P)$. All parameters are highly significant in statistical terms. In terms of magnitude, the estimated coefficients for expertise and competence (EXPT) are nearly twice the size of the coefficients for trust and identity (TRID). The role of expertise is robust across leaders and employees. Through internal self-selection, individuals who favour the relation between competence and performance should tend to bunch up in business units and departments that accommodate this inclination. As emphasized by previous studies of the impact of active $H R$ management (e.g., Lado and Wilson, 1994), our results clearly suggest that a predilection for proficiency has a reward in terms of career opportunities, not only among leaders, but also for 
their employees.

Trust and identity (TRID) are also important for perceptions of career opportunities, according to our results. Again, the estimated coefficients are positive, sizeable and highly significant in statistical terms. Recall that this variable captures trust both in the immediate leader as well as in corporate management. In principle, TRID therefore covers both relationship-based trust and the character-based perspective of trust, which is especially relevant for more distant leaders than one's immediate superior (Dirks and Ferrin, 2002). However, there is reason to believe that the relationship-based perspective dominatesin the evaluation of career opportunities, and our results should be interpreted accordingly. The estimated model clearly suggests that perceived career opportunities among leaders and employees are strongly influenced by leadership qualities associated with trust.

Finally, it might seem somewhat puzzling that the impact of HSE concerns (HSEC) actually changes sign between our two model specifications for performance appraisal. An HSE-oriented work environment is negative for the content with performance appraisal systems $(P A)$, at least for employees. On the other hand, the same variable exerts a positive influence on perceived career opportunities. This positive effect is especially strong for leaders, and we take this as a reflection of the inclusion of HSE results in the performance contracts of leaders in Statoil. Along the same lines of thought, we may see the positive connection between HSE awareness and career opportunities for employees as a manifestation of the stated objective that health, safety and environment should be an important part of the mindset of anyone who wants to make their career with Statoil.

\section{Summary and concluding remarks}

The interest in human capital management has increased over the last 10 years, reflecting both shortages and increased value-creating potential for human resources, skills and competence. Important reasons behind this development include strong employment growth in the OECD area, especially in skill-intensive industries. To attract and develop talents for key positions and leadership, individual incentive schemes and performance-based remuneration have become increasingly popular throughout private industries and recently also in public enterprise.

Based on a large and unique set of survey data, this study provides robust empirical explanations for perceptions regarding performance appraisal and career opportunities among leaders and employees in an international oil and gas company in Western Europe. An econometric model for categorical choice is specified and estimated, with historical and forward-looking performance appraisal as dependent variables. The models are estimated for the full sample of responders, with supplementary model versions for sub-samples of leaders and employees without leadership responsibilities, respectively.

There is still surprisingly little research on the effect of performance appraisal in the economics literature. Compared to cross-sectional studies such as Grund and Sliwka (2009), Barth et al. (2008), and Lemieux et al. (2009), our firm study put more emphasis on how performance appraisal depends on variations in properties and characteristics of the local working environment.

In terms of results, we find a significant gender effect in perceived performance appraisal, as men generally tend to report a larger gap between efforts and rewards than women. We also find that the perceived gap between efforts and rewards increases with time of service, especially for people without leadership responsibilities. Moreover, we find that various properties and characteristics of the local working environment are decisive for perceptions of performance appraisal and career opportunities, both for leaders and their employees. Parts of the organisation with exposure to competitive markets, agility and performance pressures report a somewhat higher alignment of efforts and rewards than more sheltered parts of the organisation. The same alignment is more prevalent in organisational units characterised by a significant pace of change than it is in stable and stagnant parts of the organisation. On the other hand, career opportunities seem to be negatively affected by restructuring and change, especially among leaders. In line with previous literature, we find that the functioning of performance appraisal systems depends positively on trust and identity issues, whereas high HSE concerns in the local working environment seem to increase the perceived gap between efforts and rewards.

In terms of strategy and policy implications, our results may prove useful in several aspects. A reasonable assumption is that an objective of human resource management would be to minimise the gap between expected and realised rewards, and to align the balance between individual performance and personal appraisal. Our results suggest that such imbalances are a larger problem among men than women. Moreover, perceived gratification seems to fall with time of service, especially among employees lacking management responsibilities. In a similar fashion, the estimated influence of various characteristics of the local working environment also provides indications for how to allocate management resources across the organisation. As an example, the perceived gap between efforts and rewards is higher in sheltered parts of the organisation than in organisational 
units marked by competitive performance.

The present study has identified some important drivers for the perception of performance appraisal systems. At the same time, certain shortcomings are still implied by limitations of our data and scope of research. First, the data set of our study is purely cross-sectional. A potential route for further sophistication would be to study survey data over several years, ideally speaking with time series for each individual. This would allow the study of how perceptions of performance appraisal may change over time, due to changes in explanatory variables and other exogenous shocks at the individual, organisational, company or industry level. Second, our investigation is limited to perceptions regarding the gap between efforts and rewards. Data for actual outcomes in terms of efforts and performance appraisal at the individual level would allow us to study the variation between perceived and actual performance appraisal. These are issues left for future research.

\section{Acknowledgements}

For useful comments and advice, the authors would like to thank Einar Brandsdal, Håvard Hansen, Knud Knudsen, Gro Ellen Mathiesen, Torvald Øgaard, and seminar participants at the University of Stavanger. The usual disclaimer applies.

\section{References}

Barth, E., Bratsberg, E., Hægeland, T., and Raaum, O. (2008). Who pays for performance? International Journal of Manpower, 29(1), 8-29. http://dx.doi.org/10.1108/01437720810861985

Boswell, M., and Benson, J. (2000). Employee satisfaction with performance appraisals andappraisers: The role of perceived appraisal use. Human Resource Development Quarterly, 11(3), 283-299. http://dx.doi.org/10.1002/1532-1096(200023)11:3<283::AID-HRDQ6>3.0.CO;2-3

Brouwer, M. (2005). Incentive pay and uncertainty in entrepreneurial and bureaucratic firms. Working Paper, Department of Economics, University of Amsterdam.

Brown, M., and Benson, J. (2003). Rated to exhaustion? Reactions to performance appraisal Processes. Industrial Relations Journal, 34(1), 76-81. http://dx.doi.org/10.1111/1468-2338.00259

Brown, M., and Heywood, J. S. (2005). Performance appraisal systems: determinants and change. British Journal of Industrial Relations, 43, 659-679. http://dx.doi.org/10.1111/j.1467-8543.2005.00478.x

Cleveland J. N., Murphy K. R., and Williams, R. E. (1989). Multiple Uses of Performance Appraisal: Prevalence and Correlates. Journal of Applied Psychology, 74(1), 130 - 135. http://dx.doi.org/10.1037//0021-9010.74.1.130

Cronbach, L. J. (1951). Coefficient Alpha and the Internal Structure of Tests. Psychometrika, 16(3), 297 - 334. http://dx.doi.org/10.1007/BF02310555

Dirks, K. T., and Ferrin, D. L. (2002). Trust in leadership: meta-analytic findings and implications for research. Journal of Applied Psychology, 87(4), 611-628. http://dx.doi.org/10.1037//0021-9010.87.4.611

Donohue, S. M., and Heywood, J. S. (2004). Job satisfaction and gender: an expanded specification from the NLSY. International Journal of Manpower, 25(2), 211-234.

Gebris, G. T., and Ihrke, D. M. (2000). Improving employee acceptance toward performance appraisal and merit pay systems. Review of Public Personnel Administration, 20(1), 41-53.

Greene, W. H. (2003). Econometric Analysis. (5 ${ }^{\text {th }}$ ed.). New Jersey: Prentice Hall.

Grund, C., and Sliwka, D. (2009). The anatomy of performance appraisals in Germany. The International Journal of Human Resource Management, 20(10), 2049 - 2065. http://dx.doi.org/10.1080/09585190903175613

Hennequin, E. (2007). What "career success" means to blue-collar workers. Career Development International, 12(6), 565-581.

Hind, P., and Baruch, Y. (1997). Gender variations in perceptions of performance appraisal. Women in Management Review, 12(7), 276-289.

Jovanovic. B. (1979). Job matching and the theory of turnover. Journal of Political Economy, 87, 972-90. http://dx.doi.org/10.1086/260808

Keeping, L.M and Levy, P. E. (2000). Performance appraisal reactions. Measurement, modelling, and method bias. Journal of Applied Psychology, 85, 708-723. http://dx.doi.org/10.1037//0021-9010.85.5.708

Kickul, J., Gundry, L. K., and Posig, M. (2005). Does trust matter? The relationship between equity sensitivity and perceived organisational justice. Journal of Business Ethics, 56, 205-218. 
http://dx.doi.org/10.1007/s10551-004-0992-0

King, J. E. (2000). White-collar reactions to job insecurity and the role of the psychologicalcontract: implications for human resource management. Human Resource Management, 39(1), 79-92. http://dx.doi.org/10.1002/(SICI)1099-050X(200021)39:1<79::AID-HRM7>3.0.CO;2-A

Koys, D. J., Keaveny, T. J., and Allen, R. E. (1989). Employment demographics and attitudes that predict preferences for alternative pay increase policies. Journal of Business and Psychology, 4(1), 27-47.

Kuvaas, B. (2006). Performance appraisal satisfaction and employee outcomes: mediating andmoderating roles of work motivation. International Journal of Human Resource Management, 17(3), 504-522. http://dx.doi.org/10.1080/09585190500521581

Kvaløy, O., and Olsen, T. (2011).The rise of individual performance pay. CESifo Working Paper no. 2145. November 2007. Forthcoming. Journal of Economics \& Management Strategy.

Lado, A. A., and Wilson, M. C. (1994). Human resource systems and sustained competitive advantage: a competency-based perspective. Academy of Management Review, 19(4), 699-727. http://dx.doi.org/10.5465/AMR.1994.9412190216

Lazear, E. P. (1990). The timing of raises and other payments. Carnegie-Rochester Conference Series in Public Policy. http://dx.doi.org/10.1016/0167-2231(90)90005-6

Lazear, E. P. (1998). Personnel Economics for Managers. New York: John Wiley and Sons.

Lemieux, T., MacLeod, W. B., and Parent, D. (2009). Performance Pay and Wage Inequality. Quarterly Journal of Economics, 124(1), 1 - 49. http://dx.doi.org/10.1162/qjec.2009.124.1.1

Levy, P. E., and Williams, J. R. (2004). The social context of performance appraisal: areviewand framework for the future. Journal of Management, 30(6), 881-905.

MacLeod, W. B. (2003). Optimal contracting with subjective evaluation. American Economic Review, 93, 216-240. http://dx.doi.org/10.1257/000282803321455232

Marsden, D. (2004). The role of performance-related pay in renegotiating the "effort bargain": the case of the British public service. Industrial and Labour Relations Review, 57(3), 350-370. http://dx.doi.org/10.2307/4126656

Milkovich, G. T., and Wigdor, A. K. (1991). Pay for performance. Evaluating performance appraisal and merit pay. Washington DC: National Academy Press.

Offstein, E. H., Gnyawali, D. R., and Cobb, A. T. (2005). A strategic human resource perspective of firm competitive behaviour. Human Resource Management Review, 15, 305-318. http://dx.doi.org/10.1016/j.hrmr.2005.11.007

Pett. M., Lackey, N. R., and Sullivan, J. J. (2003). Making sense of factor analysis. Thousand Oaks (CA): Sage.

Prendergast, C. (1999). The provision of incentives in firms. Journal of Economic Literature, 37, 7-63. http://dx.doi.org/10.1257/jel.37.1.7

Reinke, S. R. (2003). Does the form really matter? Review of Public Personnel Administration, 23(1), 23-37. http://dx.doi.org/10.1177/0734371X02250109

Svetlik, I., and Stavrou-Costea, E. (2007). Connecting human resources management and knowledge management. International Journal of Manpower, 28(3/4), 197-206.

Sweeney, P. D., and McFarlin, D. B. (1997). Process and outcome: gender differences in the assessment of

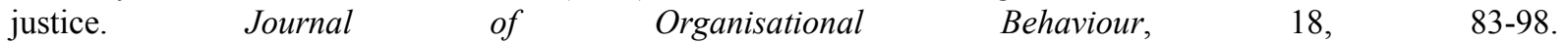
http://dx.doi.org/10.1002/(SICI)1099-1379(199701)18:1<83::AID-JOB779>3.0.CO;2-3

Taylor, M. S., Masterson, S. S., Renard, M. K., \& Tracy, K. B. (1998). Managers' reactions to procedurally just performance systems. Academy of Management Journal, 41(5), 568-579. http://dx.doi.org/10.2307/256943

Wooldridge, J. M. (2003). Econometric Analysis of Cross Section and Panel Data. Cambridge: MIT Press.

Zaheer, A., McEvily, B., and Perrone, V. (1998). Does trust matter? Exploring the effects of interorganizational and interpersonal trust on performance. Organizational Science, 9(2), 141-159. http://dx.doi.org/10.1287/orsc.9.2.141

Zavoina, R., and McElvey, W. (1975). A statistical model for the analysis of ordinal level dependent variables. Journal of Mathematical Sociology, Summer 1975, 500-509. 


\section{Notes}

Note 1. Invitations to participate are sent by e-mail to all relevant employees, and followed up with two reminders over the survey period. Respondents submit their response directly in a series of questionnaires through an inter-active web-based design, and are expected to spend around 20 minutes on their response. Data are then collected, and stored and studied by the HR department at the corporate center, before relevant sub-samples of results are distributed to leaders throughout the organization for follow-up at all levels of the organization. Observe that Statoil's Global People Survey 2006 was designed and conducted by the company itself, without our influence or interaction. Our point of departure is formed by the questionnaire and the individual responses.

Note 2. In a theoretical model, Brouwer (2005) also argues that self-selection is a potential source for this kind of systematic difference between entrepreneurial and bureaucratic firms, whereby assertive and bold individuals (risk-lovers) seek opportunities with entrepreneurial firms, while mindful and unsure individuals (risk-haters) tend to pursue a career with more bureaucratic firms or organisations.

Note 3. Observe, however, that the direction of the effect of a change in $x(z)$ is unambiguously determined by the sign of $\beta(\gamma)$ only for the probabilities of the worst score $(p(y=1 \mid x, z))$ and the top score $(p(y=6 \mid x, z))$. For intermediate scores $(2,3,4$, and 5$)$, the sign of partial effects is not uniquely determined by the sign of the coefficients. However, the model can be applied for prediction, whereby the role of exogenous variables is explored for each outcome by comparative analyses. Specifically, estimates of expected outcomes can be compared for various levels of the explanatory variables to obtain partial effects for each of the outcomes.

Note 4. Prior to running the ordered probit model we applied the OLS estimator. The estimated numbers are not reported since all the signs and the overall results are the same as in the probit framework. We interpret this as an indication of robustness of our econometric analysis.

Note 5. To test for the influence of intragroup correlation, preliminary estimations were run with clustered standard errors for a range of background variables. However, the significance of our estimated effects shows robustness to these alternative estimation procedures. To keep things simple, we therefore stick to the simple version of standard errors in our presented calculation of p-values.

Note 6. This pseudo $R^{2}$ measure is computed because there is no direct equivalent of a traditional $R^{2}$ (from OLS regression) in non-linear models like the ordered probit model. Compared to standard econometric on time series data, our pseudo $R^{2}$ estimates may seem to indicate weak statistical fit. However, this level of statistical fit is not uncommon for non-linear models of discrete choice in cross-sectional data. As noted by Wooldridge (2003), goodness of fit is not as important as statistical and economic significance of the variables in this class of models.

Note 7. On the other hand, Sweeney and McFarlin (1997) also argue that women are more concerned with procedural justice than men.

Note 8. Observe also that the concept of career success may vary between leaders and employees in non-managerial positions (Hennequin, 2007). 
Table 1. Validation of index variables.Factor analysis obtained with Stata 9.0.

\begin{tabular}{|c|c|c|}
\hline Items, index variables, and key statistics & $\lambda_{1}{ }^{\alpha)}$ & $C^{b)}$ \\
\hline \multicolumn{3}{|l|}{ Change capability $\left(C H N G ; E V_{1}=2.68 ; E V_{2}=0.01 ;\right.$ Cronbach's $\left.\alpha=0.86\right)$} \\
\hline $\begin{array}{l}\text { CHNG1: "In my entity, we have a culture which stimulates new ideas and } \\
\text { creativity" }\end{array}$ & 0.79 & 0.62 \\
\hline $\begin{array}{l}C H N G 2 \text { : "In my entity, we systematically follow up on feedback from customers } \\
\text { and clients" }\end{array}$ & 0.69 & 0.48 \\
\hline $\begin{array}{l}\text { CHNG3: "In my entity, we are good at exchanging experiences with other entities } \\
\text { in Statoil" }\end{array}$ & 0.72 & 0.52 \\
\hline CHNG4: "In my entity, suggestions for improvements are quickly put into practice" & 0.78 & 0.61 \\
\hline CHNG5: "My superior is good at implementing improvements" & 0.68 & 0.47 \\
\hline \multicolumn{3}{|l|}{ Expertise (EXPT; $E V_{1}=3.27 ; E V_{2}=0.06$; Cronbach's $\alpha=0.88$ ) } \\
\hline EXPT1: "I am able to utilise my expertise and abilities in my daily work" & 0.67 & 0.47 \\
\hline $\begin{array}{l}\text { EXPT2: "Conditions are favourable for me to continue my personal development } \\
\text { in a systematic manner" }\end{array}$ & 0.84 & 0.71 \\
\hline EXPT3: "I receive the training required to do a good job" & 0.73 & 0.55 \\
\hline EXPT4: "I take the initiative and actively seek to develop my skills" & 0.65 & 0.45 \\
\hline $\begin{array}{l}\text { EXPT5: "In my entity, we are good at making use of each other's expertise } \\
\text { and experience" }\end{array}$ & 0.80 & 0.65 \\
\hline $\begin{array}{l}\text { EXPT6: "My leader creates favourable conditions for the development of each } \\
\text { employee" }\end{array}$ & 0.73 & 0.54 \\
\hline \multicolumn{3}{|l|}{ Trust and identity (TRID; $E V_{I}=3.53 ; E V_{2}=0.37 ;$ Cronbach's $\alpha=0.87$ ) } \\
\hline TRID1: "I have confidence in the management of my business unit" & 0.81 & 0.68 \\
\hline TRID2: "I have confidence in the corporate executive committee" & 0.75 & 0.63 \\
\hline TRID3: "I speak of Statoil to my friends as a good company to work for" & 0.66 & 0.47 \\
\hline TRID4: "In my entity, we respect the individual" & 0.68 & 0.59 \\
\hline TRID5: "In my entity, we may challenge accepted truths" & 0.69 & 0.60 \\
\hline $\begin{array}{l}\text { TRID6: "Cooperation between management and the trade unions in my business } \\
\text { unit is good" }\end{array}$ & 0.72 & 0.55 \\
\hline $\begin{array}{l}\text { TRID7: "I am confident that Statoil contributes to sustainable development and } \\
\text { displays social responsibility wherever it has operations" }\end{array}$ & 0.65 & 0.48 \\
\hline$H S E$ consciousness (HSEC; $E V_{1}=2.27 ; E V_{2}=0.15$; Cronbach's $\alpha=0.81$ ) & & \\
\hline $\begin{array}{l}\text { HSEC1: "In my entity, the zero mindset (zero accidents, harm and losses) forms } \\
\text { the basis for planning and implementing our work" }\end{array}$ & 0.66 & 0.48 \\
\hline $\begin{array}{l}\text { HSEC2: "In my entity, we are good at exploiting diversity (of backgrounds, age, } \\
\text { gender, and abilities)" }\end{array}$ & 0.71 & 0.53 \\
\hline $\begin{array}{l}\text { HSEC3: "In my entity, tasks which could entail risk are always performed } \\
\text { according to established procedures" }\end{array}$ & 0.66 & 0.48 \\
\hline HSEC4: "I get support from my colleagues if I find difficulties in solving my tasks" & 0.63 & 0.40 \\
\hline $\begin{array}{l}\text { HSEC5: "Tasks in my workplace are organised in accordance with the capabilities } \\
\text { of the individual employee" }\end{array}$ & 0.71 & 0.53 \\
\hline
\end{tabular}

a) Factor loadings. b) Communality. Data source: StatoilHydro, Global People Survey 2006. 
Table 2. Descriptive statistics for data sample

\begin{tabular}{|l|c|c|c|c|c|c|}
\hline & \multicolumn{2}{|c|}{$\begin{array}{c}\text { Full sample } \\
(N=12366)\end{array}$} & \multicolumn{2}{c|}{$\begin{array}{c}\text { Leaders } \\
(N=1950)\end{array}$} & \multicolumn{2}{c|}{$\begin{array}{c}\text { Employees } \\
(N=10416)\end{array}$} \\
\hline & Mean & St. dev. & Mean & St. dev. & Mean & St. dev. \\
\hline PA & 4.057 & 1.220 & 4.511 & 1.073 & 3.973 & 1.227 \\
CO & 4.444 & 1.172 & 4.774 & 1.061 & 4.384 & 1.182 \\
\hline CHNG & 4.186 & 0.871 & 4.505 & 0.747 & 4.128 & 0.880 \\
EXPT & 4.326 & 0.856 & 4.641 & 0.736 & 4.269 & 0.864 \\
TRID & 4.667 & 0.784 & 5.017 & 0.626 & 4.603 & 0.842 \\
HSEC & 4.693 & 0.727 & 4.923 & 0.607 & 4.651 & 0.739 \\
\hline
\end{tabular}

Data source: StatoilHydro, Global People Survey 2006.

Table 3. Estimated perception of performance appraisal (PA model) and career opportunities (CO model). Ordered probit estimates obtained with Stata 9.0

\begin{tabular}{|c|c|c|c|c|c|c|}
\hline & \multicolumn{3}{|c|}{ PA model } & \multicolumn{3}{|c|}{ CO model } \\
\hline & Full sample & Leaders & Employees & Full sample & Leaders & Employees \\
\hline \multicolumn{7}{|l|}{ Estimated coefficients $^{a)}$} \\
\hline \multirow{2}{*}{ Female } & $0.108^{* * *}$ & $0.205^{* * *}$ & $0.110^{* * *}$ & $0.076^{* * *}$ & 0.034 & $0.091^{* * *}$ \\
\hline & $(0.000)$ & $(0.001)$ & $(0.000)$ & $(0.001)$ & $(0.581)$ & $(0.000)$ \\
\hline \multirow{2}{*}{ Seniority 1 (3-10 yrs) } & -0.032 & $0.243^{* *}$ & $-0.079^{* * *}$ & $-0.313^{* * *}$ & -0.121 & $-0.345^{* * *}$ \\
\hline & $(0.276)$ & $(0.021)$ & $(0.013)$ & $(0.000)$ & $(0.273)$ & $(0.000)$ \\
\hline \multirow{2}{*}{ Seniority 2 (> 10 yrs) } & $-0.076^{* * *}$ & 0.107 & $-0.128^{* * *}$ & $-0.347^{* * *}$ & $-0.193^{*}$ & $-0.389^{* * *}$ \\
\hline & $(0.007)$ & $(0.269)$ & $(0.000)$ & $(0.000)$ & $(0.062)$ & $(0.000)$ \\
\hline \multirow{2}{*}{$C H N G$} & $0.542^{* * *}$ & $0.436^{* * *}$ & $0.561^{* * *}$ & $-0.254^{* * *}$ & $-0.291^{* * *}$ & $-0.250^{* * *}$ \\
\hline & $(0.000)$ & $(0.000)$ & $(0.000)$ & $(0.000)$ & $(0.000)$ & $(0.000)$ \\
\hline \multirow{2}{*}{$E X P T$} & $0.418^{* * *}$ & $0.442^{* * *}$ & $0.408^{* * *}$ & $0.886^{* * *}$ & $0.938^{* * *}$ & $0.876^{* * *}$ \\
\hline & $(0.000)$ & $(0.000)$ & $(0.000)$ & $(0.000)$ & $(0.000)$ & $(0.000)$ \\
\hline \multirow{2}{*}{$T R I D$} & $0.320^{* * *}$ & $0.405^{* * *}$ & $0.290^{* * *}$ & $0.410^{* * *}$ & $0.536^{* * *}$ & $0.386^{* * *}$ \\
\hline & $(0.000)$ & $(0.000)$ & $(0.000)$ & $(0.000)$ & $(0.000)$ & $(0.000)$ \\
\hline \multirow{2}{*}{ HSEC } & $-0.074^{* * *}$ & -0.007 & $-0.079^{* * *}$ & $0.223^{* * *}$ & $0.322^{* * *}$ & $0.215^{* * *}$ \\
\hline & $(0.001)$ & $(0.911)$ & $(0.000)$ & $(0.000)$ & $(0.000)$ & $(0.000)$ \\
\hline \multicolumn{7}{|l|}{ Model diagnostics } \\
\hline \multirow{2}{*}{$\chi^{2}()$} & $7238.68^{* * *}$ & $887.32^{* * *}$ & $6082.17^{* * *}$ & $7742.19^{* * *}$ & $1103.54^{* * *}$ & $6483.85^{* * *}$ \\
\hline & $(0.000)$ & $(0.000)$ & $(0.000)$ & $(0.000)$ & $(0.000)$ & $(0.000)$ \\
\hline Pseudo $R^{2}$ & 0.19 & 0.16 & 0.19 & 0.21 & 0.21 & 0.21 \\
\hline Obs (\#) & 12368 & 1950 & 10418 & 12623 & 1957 & 10666 \\
\hline
\end{tabular}

*) Significant at 90,**) 95 and ***) 99 per cent confidence level, respectively.

a) p-values in brackets. 
Performance Appraisal (perception)

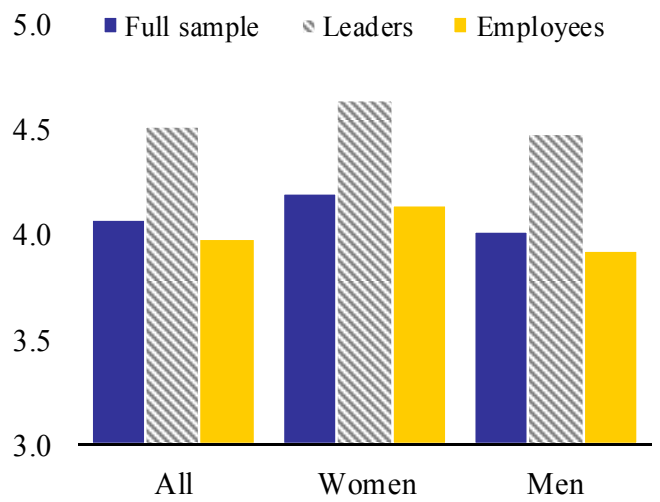

Career opportunities (perception)

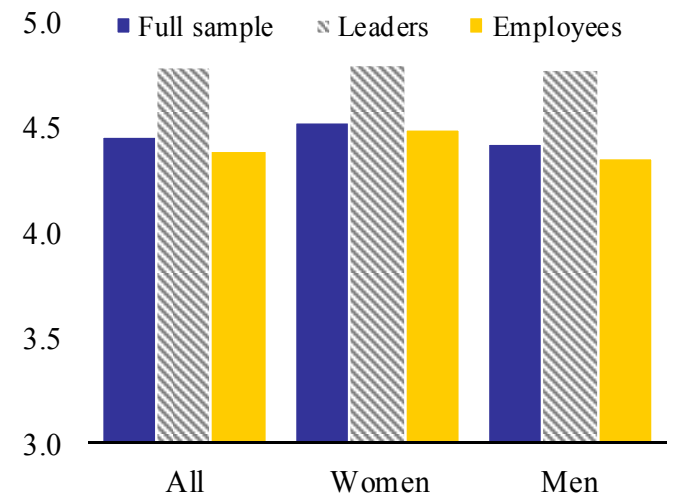

Figure 1. Average scores from Statoil's Global People Survey 2006 Source: StatoilHydro.

\section{Appendix 1. Average scores for the dependent variables}

Performance Appraisal Perception (PAP)

\begin{tabular}{|lcccc|}
\hline & $\begin{array}{c}\text { Seniority } 1 \\
(<3 \text { years })\end{array}$ & $\begin{array}{c}\text { Seniority } 2 \\
(3-10 \quad \text { years })\end{array}$ & $\begin{array}{c}\text { Seniority } 3 \\
(>10\end{array}$ years $)$ & Total \\
\hline $\begin{array}{l}\text { Full sample }(N=12,368) \\
\text { Men }\end{array}$ & 4.198 & 3.989 & 3.963 & \\
Women & 4.434 & 4.203 & 4.101 & 4.007 \\
All & 4.268 & 4.051 & 3.998 & 4.192 \\
& & & & \\
\hline Leaders & 4.473 & 4.496 & 4.471 & 4.477 \\
Men & 4.529 & 4.763 & 4.601 & 4.635 \\
Women & 4.493 & 4.557 & 4.497 & 4.511 \\
All & & & & \\
& 4.179 & 3.909 & 3.821 & 3.911 \\
Employees & 4.424 & 4.142 & 4.009 & 4.129 \\
Men & 4.251 & 3.979 & 3.873 & 3.973 \\
Women & & & & \\
All & & & & \\
\hline
\end{tabular}

Career opportunities $(\mathrm{COP})$

\begin{tabular}{|lcccc|}
\hline & $\begin{array}{c}\text { Seniority } 1 \\
(<3 \text { years })\end{array}$ & $\begin{array}{c}\text { Seniority } 2 \\
(3-10 \quad \text { years })\end{array}$ & $\begin{array}{c}\text { Seniority } 3 \\
(>10 \quad \text { years })\end{array}$ & Total \\
\hline Full sample $(N=12,623)$ & 4.809 & 4.367 & & \\
Men & 4.870 & 4.494 & 4.329 & 4.416 \\
Women & 4.828 & 4.404 & 4.398 & 4.518 \\
All & & 4.347 & 4.444 \\
\hline & & & \\
Leaders & 4.955 & 4.725 & 4.771 & 4.769 \\
Men & 4.694 & 4.838 & 4.783 & 4.787 \\
Women & 4.861 & 4.751 & 4.773 & 4.774 \\
All & & & & \\
\hline & & & & \\
Employees & 4.800 & 4.311 & 4.206 & 4.344 \\
Men & 4.884 & 4.458 & 4.328 & 4.482 \\
Women & 4.826 & 4.355 & 4.239 & 4.384 \\
All & & & & \\
\hline
\end{tabular}

